\title{
A step forward for understanding the morbidity burden in Guinea: a national descriptive study
}

\author{
Keita Mamady and Guoging $\mathrm{Hu}^{*}$
}

\begin{abstract}
Background: Little evidence on the burden of disease has been reported about Guinea. This study was conducted to demonstrate the morbidity burden in Guinea and provide basic evidence for setting health priorities.

Methods: A retrospective descriptive study was designed to present the morbidity burden of Guinea. Morbidity data were extracted from the National Health Statistics Report of Guinea of 2008. The data are collected based on a pyramid of facilities which includes two national hospitals (teaching hospitals), seven regional hospitals, 26 prefectural hospitals, 8 communal medical centers, 390 health centers, and 628 health posts. Morbidity rates were calculated to measure the burden of non-fatal diseases. The contributions of the 10 leading diseases were presented by sex and age group.

Results: In 2008, a total of 3,936,599 cases occurred. The morbidity rate for males was higher than for females, 461 versus 332 per 1,000 population. Malaria, respiratory infections, diarrheal diseases, helminthiases, and malnutrition ranked in the first 5 places and accounted for $74 \%$ of the total burden, respectively having a rate of $148,64,33,32$, and 14 per 1,000 population. The elderly aged $65+$ had the highest morbidity rate (611 per 1,000 population) followed by working-age population (458 per 1,000 population) and children (396 per 1,000 population) while the working-age population aged 25-64 contributed the largest part (39\%) to total cases. The sex- and age-specific spectrum of morbidity burden showed a similar profile except for small variations.

Conclusion: Guinea has its unique morbidity burden. The ten leading causes of morbidity burden, especially for malaria, respiratory infections, diarrheal diseases, helminthiases, and malnutrition, need to be prioritized in Guinea.
\end{abstract}

\section{Background}

A consistent description of the burden of diseases and injuries, and the risk factors associated with them, is an important input to health decision-making and planning processes [1]. The Global Burden of Disease (GBD) Study that was initiated in the early 1990s [2-4] provides a comprehensive assessment of the disease burden for all regions of the world, and yields important evidence for priority setting in health policy and research, and for the development of cost-effective health interventions. Since the GBD study introduced the disability-adjusted life year (DALY) - a single measure to quantify the burden of diseases, injuries and risk factors - in some countries, more and more countries have begun to use the DALY to set health priorities and support health decision-making [5-8].

\footnotetext{
* Correspondence: huguoging009@gmail.com

Department of Epidemiology and Health Statistics, School of Public Health, Central South University, 110 Xiangya Road, 410078 Changsha, China
}

As one of the least developed countries in the world, the Republic of Guinea (usually called Guinea) is characterized by high levels of vulnerability, mortality and malnutrition, limited access to basic social services, loss of coping mechanisms, and galloping spread of HIV/ AIDS [9]. According to the Human Development Report $2007 / 2008$, Guinea ranks 160th out of 177 countries in the ranking of human development index [10]. A number of health indicators of Guinea are among the most worrisome in the West Africa subregion [11].

Evidence-based health decision-making is especially important for Guinea to efficiently allocate its extremely limited health resources. On the other hand, little scientific evidence about Guinea has been produced in support of health decision-making up to now. We found very few scientific reports about the population health of Guinea through MEDLINE and search engines (like GOOGLE and YAHOO), and no mention of the disease burden. The GBD study included Guinea in the group

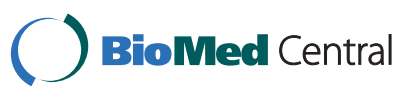

(C) 2011 Mamady and Hu; licensee BioMed Central Ltd. This is an Open Access article distributed under the terms of the Creative Commons Attribution License (http://creativecommons.org/licenses/by/2.0), which permits unrestricted use, distribution, and reproduction in any medium, provided the original work is properly cited. 
of low- and middle-income countries in Africa, and reported the disease burden of this group rather than of each nation [1]. An early study in 1996 by Jha et al [12] reported the burden of disease based on mortality data. However the disease burden of Guinea might have changed in the past 12 years, and mortality alone does not convey the total burden of disease.

In addition, Guinea has the same problem of knowledge translation as most developing countries [13,14]. Few health officials are able to make full use of data to support their decision-making due to various reasons. The objective of this present study is to provide quantitative estimations of the national burden of non-fatal diseases for Guinea.

\section{Methods}

Data

A retrospective descriptive study was designed to demonstrate the morbidity burden of Guinea. The number of cases for calculating morbidity rates came from the Guinean Annual Health Statistics report 2008. Guinean Annual Health Statistics reports are based on the national data collection system. The national data collection system is a pyramid of facilities, comprising two national hospitals (teaching hospitals), seven regional hospitals, 26 prefectural hospitals, 8 communal medical centers, 390 health centers, and 628 health posts [15]. The data for all cases are recorded by highly trained health workers (doctors and nurses). With the help from WHO and other partners of development, Guinea uses standard clinical and laboratory methods to diagnose the cause of diseases [16]. The national public heath laboratory of Guinea regularly inspects all the laboratories and offers up-to-date training to laboratory assistants at local levels, so as to improve the quality of the laboratory results [15].

Skilled statisticians collect and process the data; then, send them to the Department of Health Information at the Ministry of Public Health, where a team of scientific community and specialized health experts validate the data and produce the annual health statistics report [15]. The complex health conditions that cannot be dealt with at health centers and posts are immediately referred to the prefectural hospital (the communal medical center is only at the level of the capital city, Conakry). In each region, there is a medical officer who coordinates and inspects the provision of health services and other activities such as regular organization of an intensive educational campaign to improve the quality, accuracy and reliability of health data. Guinea's population was estimated to be $9,958,190$ inhabitants in 2008 , on the basis of estimates of the 1996 census [15].

\section{Analysis}

We did not calculate the disability adjusted life years (DALYs) to measure the disease burden due to the absence of basic indicators, because Cooper et al [17] pointed out that GBD projections from sub-Saharan Africa should not be used until data are available which correspond with modeled estimates. Mortality rates were excluded from this study because of the unavailability of fatal data in the Guinean Annual Health Statistics report 2008.

Morbidity rates were used to measure the burden of non-fatal diseases, calculated as the number of cases divided by the population $\times 1,000$. The relative contributions of diseases were presented by sex and age group separately, since obvious sex and age differences were reported in the global burden of disease study [6]. We divided age into five groups: 0-4 years, 5-14 years, 15-24 years, 25-64 years, and 65 years and over. The Guinean health statistics report provides the data for 52 common and prevalent diseases. The 10 leading causes of diseases were presented to highlight the most important sources of morbidity burden, because they already accounted for more than $80 \%$ of the total morbidity rate for each sexand age-specific group.

\section{Results}

A total of 3,936,599 cases occurred in 2008, of which $57 \%$ were males and $43 \%$ were females (Table 1 ). The morbidity rate for males was higher than for females, 461 versus $332 / 1,000$ population. The old adults aged $65+$ had the highest morbidity rate $(611 / 1,000)$ followed by the working-age population aged 25-64 (458.2/1,000) and children (396.4/1,000); the working-age population contributed the largest part (39\%) to total cases.

For the whole population, malaria, respiratory infections, diarrheal diseases, helminthiases, and malnutrition ranked in the first 5 places and accounted for $74 \%$ of the total burden, respectively having rates of 148, 64, 33, 32 , and 14/1,000 population (Figure 1).

In males, malaria, respiratory infections were the most common diseases for all age groups (Table 2). Diarrheal disease, helminthiases, and malnutrition held the other top 5 places except for the age groups of 15-24 and 2564 , where injuries replaced malnutrition in the 5 th place. The next 5 leading causes of diseases varied with age group. For instance, boys under 5 years experienced anemia, dermatologic diseases, ear-nose-throat infections, measles, and injuries. While for the elderly aged $65+$, gastritis and ulcers, dermatologic diseases, injuries, hypertension, and articular diseases took the 6th to 10th places.

In females, malaria was the first leading cause of diseases, as in males (Table 3). But for women/girls aged 
Table 1 Morbidity rate/1,000 population in Guinea, 2008

\begin{tabular}{|c|c|c|c|c|}
\hline Variables & Number of cases & Population & Percentage of cases & Morbidity rate/1,000 population \\
\hline Total & 3936599 & 9958190 & $100 \%$ & 395 \\
\hline \multicolumn{5}{|l|}{ Sex } \\
\hline Male & 2242328 & 4860649 & $57 \%$ & 461 \\
\hline Female & 1694271 & 5097541 & $43 \%$ & 332 \\
\hline \multicolumn{5}{|l|}{ Age group } \\
\hline $0-4$ & 701155 & 1768670 & $18 \%$ & 396 \\
\hline $5-14$ & 981218 & 2767748 & $25 \%$ & 355 \\
\hline $15-24$ & 451299 & 1641504 & $12 \%$ & 275 \\
\hline $25-64$ & 1520625 & 3318445 & $39 \%$ & 458 \\
\hline $65+$ & 282302 & 461823 & $7 \%$ & 611 \\
\hline
\end{tabular}

5-14 and aged 25-64, diarrheal diseases took the second place. Compared with males, the most notable difference for women was that injuries were rarely found among the 10 leading causes except for aged 25-64 (the 5th place). Another important difference was that hypertension held the 10th place for women aged 15-64.

\section{Discussion}

Our study is the first attempt to examine the non-fatal disease burden in Guinea. The morbidity rate for Guinea was 395/1,000 population in 2008; males had higher morbidity than females (461 vs. $332 / 1,000$ population); all age groups were subject to diseases, with rates changing from 275 to $611 / 1,000$ population; malaria, respiratory infections, diarrheal diseases and Helminthiases were the four leading causes of non-fatal diseases for the whole population, accounting for $70 \%$ of the morbidity burden. The order and morbidity rates of top 10 causes for sex- and age-specific groups are similar to those of the entire population except for a few differences.

The 10 leading causes of morbidity burden of Guinea are clearly different from those of the GBDS for the African region. Malaria, the first leading cause for Guinea, is absent from the three leading cause of disease for the African region based on DALYs although the

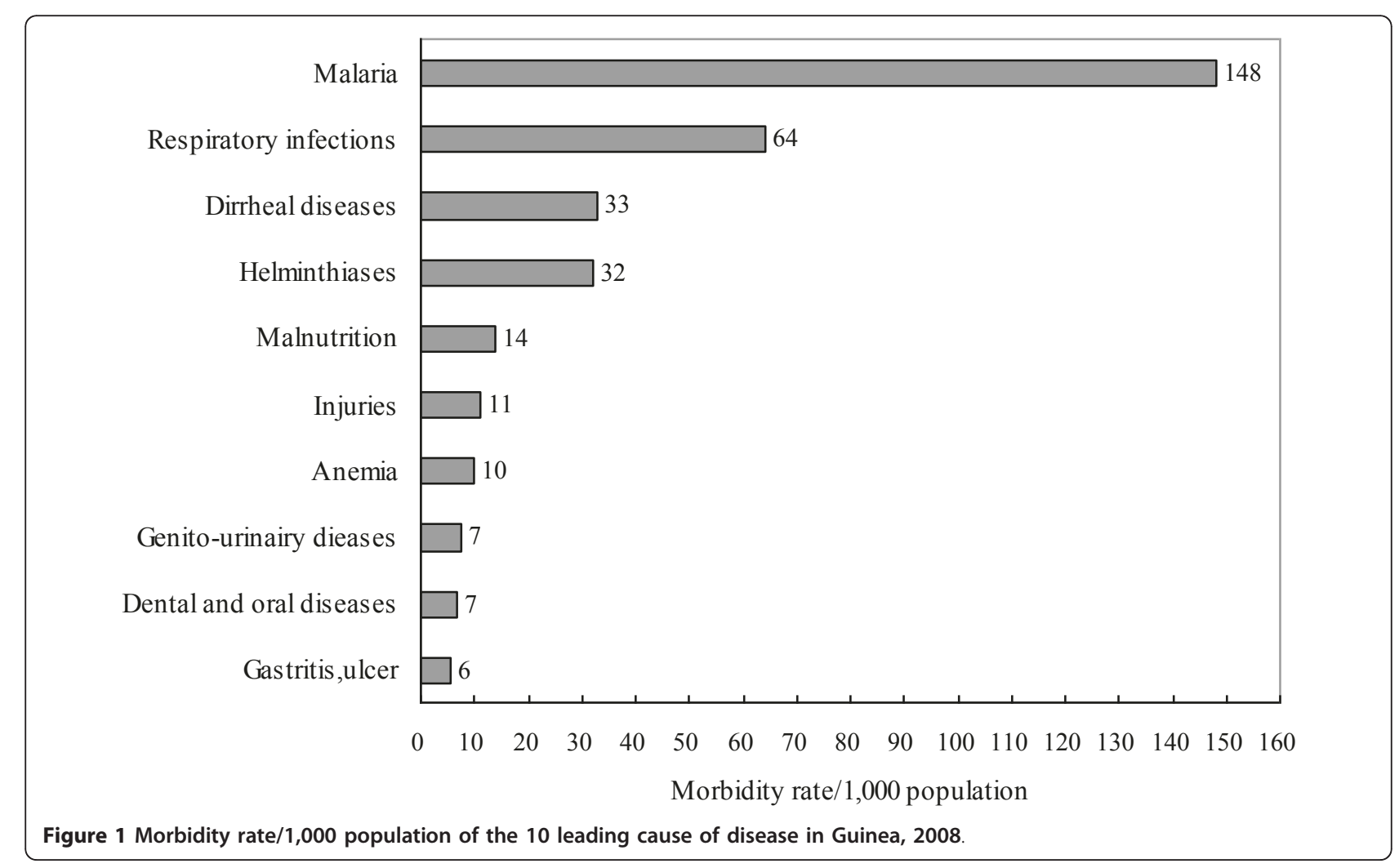


Table 2 Morbidity rates/1,000 population and percent of the 10 leading causes of diseases by age group in Guinea, (males, 2008)

\begin{tabular}{|c|c|c|c|c|c|}
\hline Rank & $0-4$ years & $5-14$ years & $15-24$ years & $25-64$ years & 65 years and over \\
\hline \multirow[t]{2}{*}{1} & Malaria & Malaria & Malaria & Malaria & Malaria \\
\hline & $174(40 \%)$ & $183(45 \%)$ & $98(31 \%)$ & $222(39 \%)$ & $146(24 \%)$ \\
\hline \multirow[t]{2}{*}{2} & Respiratory infections & Respiratory infections & Respiratory infections & Respiratory infections & Respiratory infections \\
\hline & $104(24 \%)$ & $57(14 \%)$ & $55(18 \%)$ & $99(17 \%)$ & $98(16 \%)$ \\
\hline \multirow[t]{2}{*}{3} & Diarrheal diseases & Helminthiases & Diarrheal diseases & Diarrheal diseases & Helminthiases \\
\hline & $39(9 \%)$ & $44(11 \%)$ & $23(7 \%)$ & $43(7 \%)$ & $67(11 \%)$ \\
\hline \multirow[t]{2}{*}{4} & Helminthiases & Diarrheal diseases & Helminthiases & Helminthiases & Malnutrition \\
\hline & $34(8 \%)$ & $38(9 \%)$ & $22(7 \%)$ & $28(5 \%)$ & $36(6 \%)$ \\
\hline \multirow[t]{2}{*}{5} & Malnutrition & Malnutrition & Injuries & Injuries & Diarrheal diseases \\
\hline & $16(4 \%)$ & $12(3 \%)$ & $18(6 \%)$ & $28(5 \%)$ & $29(5 \%)$ \\
\hline \multirow[t]{2}{*}{6} & Anemia & Dental and Oral diseases & Malnutrition & Dental and Oral diseases & Gastritis, ulcer \\
\hline & $8(2 \%)$ & $10(2 \%)$ & $17(6 \%)$ & $17(3 \%)$ & $26(4 \%)$ \\
\hline \multirow[t]{2}{*}{7} & Dermatologic diseases & Genito-urinairy diseases & Dermatologic diseases & Genito-urinairy diseases & Dermatologic diseases \\
\hline & $7(2 \%)$ & $9(2 \%)$ & $12(4 \%)$ & $14(2 \%)$ & $26(4 \%)$ \\
\hline \multirow[t]{2}{*}{8} & E.N.T infections & Injuries & Dental and Oral diseases & Malnutrition & Injuries \\
\hline & $6(1 \%)$ & $8(2 \%)$ & $10(3 \%)$ & $13(2 \%)$ & $24(4 \%)$ \\
\hline \multirow[t]{2}{*}{9} & Measles & Anemia & Gastritis, ulcers & Gastritis, ulcers & Hypertension \\
\hline & $6(1 \%)$ & $6(2 \%)$ & $8(3 \%)$ & $12(2 \%)$ & $23(4 \%)$ \\
\hline \multirow[t]{2}{*}{10} & Injuries & Dermatologic diseases & Anemia & Dermatologic diseases & Articular diseases \\
\hline & $5(1 \%)$ & $6(1 \%)$ & $8(3 \%)$ & $12(2 \%)$ & $19(3 \%)$ \\
\hline
\end{tabular}

Note: E.N.T infections mean ear, nose, and throat infections

Table 3 Morbidity rates/1,000 population and percent of the 10 leading causes of diseases by age group in Guinea (females, 2008)

\begin{tabular}{|c|c|c|c|c|c|}
\hline Rank & $0-4$ years & 5-14 years & 15-24 years & 25-64 years & 65 years and over \\
\hline \multirow[t]{2}{*}{1} & Malaria & Malaria & Malaria & Malaria & Malaria \\
\hline & $128(36 \%)$ & $120(41 \%)$ & $95(40 \%)$ & $124(36 \%)$ & $120(22 \%)$ \\
\hline \multirow[t]{2}{*}{2} & Respiratory infections & Diarrheal diseases & Respiratory infections & Diarrheal diseases & Respiratory infections \\
\hline & $98(27 \%)$ & $35(12 \%)$ & $34(14 \%)$ & $38(11 \%)$ & $105(19 \%)$ \\
\hline \multirow[t]{2}{*}{3} & Helminthiases & Respiratory infections & Helminthiases & Respiratory infections & Helminthiases \\
\hline & $35(10 \%)$ & $31(11 \%)$ & $23(10 \%)$ & $31(9 \%)$ & $58(11 \%)$ \\
\hline \multirow[t]{2}{*}{4} & Diarrheal diseases & Helminthiases & Anemia & Helminthiases & Anemia \\
\hline & $28(8 \%)$ & $28(9 \%)$ & $13(6 \%)$ & $28(8 \%)$ & $34.55(6 \%)$ \\
\hline \multirow[t]{2}{*}{5} & Malnutrition & Malnutrition & Malnutrition & Injuries & Malnutrition \\
\hline & $16(4 \%)$ & $11(4 \%)$ & $12(5 \%)$ & $14(4 \%)$ & $28(5 \%)$ \\
\hline \multirow[t]{2}{*}{6} & Anemia & Anemia & Diarrheal diseases & Genitourinary diseases & Hypertension \\
\hline & $6(2 \%)$ & $10(3 \%)$ & $12(5 \%)$ & $14(4 \%)$ & $24(4 \%)$ \\
\hline \multirow[t]{2}{*}{7} & E.N.T infections & Genitourinary diseases & Dental and Oral diseases & Malnutrition & Dermatologic diseases \\
\hline & $6(2 \%)$ & $9(3 \%)$ & $6(2 \%)$ & $13(4 \%)$ & $20(4 \%)$ \\
\hline \multirow[t]{2}{*}{8} & Ocular infections & Dental and Oral diseases & Articular diseases & Anemia & Articular diseases \\
\hline & $6(2 \%)$ & $7(2 \%)$ & $4(2 \%)$ & $12(3 \%)$ & $18(3 \%)$ \\
\hline \multirow[t]{2}{*}{9} & Measles & Ocular infections & Gastritis, Ulcers & Dental and Oral diseases & Gastritis, Ulcers \\
\hline & $6(2 \%)$ & $5(2 \%)$ & $4(2 \%)$ & $11(3 \%)$ & $17(3 \%)$ \\
\hline \multirow[t]{2}{*}{10} & Dermatologic diseases & Dermatologic diseases & Hypertension & Hypertension & Dental and Oral diseases \\
\hline & $5(1 \%)$ & $4(1 \%)$ & $4(2 \%)$ & $7(2 \%)$ & $15(3 \%)$ \\
\hline
\end{tabular}

Note: E.N.T infections mean ear, nose, and throat infections. 
respiratory infections and diarrheal diseases maintain the second and third positions in both studies [1]. Compared to country-based findings in Africa, our study presents findings similar to the report from sub-Saharan Africa [18] and dissimilar to the study from Tanzania [19] and South Africa [20]. In fact, there are no countries showing the same ten leading causes of diseases.

The agreement and disagreement between this study and the existing studies might be partly due to the differences in the measurement method and the year of research. On the other hand, they might strongly indicate that the burden of disease varies with nations. Würthwein et al [18] reported that the ranking of diseases in sub-Saharan Africa by the burden of disease differs substantially from the ranking in the GBDS, and suggested that local health policy should rather be based on the local burden of disease measurement instead of relying on extrapolations that might not represent the true burden of disease structure by cause.

Our findings characterize a unique spectrum of nonfatal disease burden in Guinea. On the one hand, infectious diseases are the most important threat for Guineans, such as malaria, respiratory infections, diarrheal diseases and helminthiases. The persistence of diarrhea illnesses might be due to unhygienic eating and drinking. This presence of measles as the ninth leading cause of morbidity in children under five years may reflect the low coverage of vaccination in Guinea [21].

On the other hand, non-communicable diseases and injuries are also common in Guinea as well as in other African countries [22,23]. These characteristics need to be considered when the government of Guinea prioritizes its health actions.

At the same time, we clearly realize that it is very difficult for Guinea to improve the current health situation without external efforts. Although few studies reveal the real problems in Guinea, Guinea also has serious problems similar to those in other under-developed countries, like the lack of trained health workforce [24-26], the shortage of high-quality research $[27,28]$, and the low coverage of information technology [29]. No doubt, actions are needed to increase the help from developed countries to under-developed countries.

This study was limited by the completeness and the quality of data. First, the mortality data were excluded from this study due to the unavailability of data, preventing us from presenting a complete portrait of the disease burden. Second, the real morbidity burden might be underestimated because the national health statistics report does not include patients who go to private clinics or other non-governmental facilities or are treated at home. Third, many Guineans choose traditional healers rather than hospital care because of high cost and scarcity of hospital service; for this reason, the medical records of these patients are excluded from data collection, thus leading to the underestimation of morbidity rate [30]. Fourth, the classification of diseases of the national health statistics report and the lack of related parameters prevented us from calculating the burden of non-fatal diseases using the years lost due to disability.

\section{Conclusions}

To conclude, the ten leading causes account for about $90 \%$ of total morbidity burden, and should be prioritized in Guinea. Actions are also needed to improve the health information system so as to provide accurate, complete, and timely evidence for decision-making.

\section{List of abbreviations}

GBD: global burden of disease; DALY: the disability-adjusted life year.

\section{Acknowledgements}

This study was supported by the 2009 New Central Scholar Support Grant of Ministry of Education of China (NCET-10-0782).

\section{Authors' contributions}

$\mathrm{KM}$ and $\mathrm{GH}$ conceived of the idea, completed data analysis and wrote the paper. Both authors read and approved the final manuscript.

\section{Competing interests}

The authors declare that they have no competing interests.

Received: 1 November 2010 Accepted: 6 June 2011

Published: 6 June 2011

\section{References}

1. World Health Organization: The global burden of disease: 2004 update. Geneva: World Health Organization; 2008.

2. World Bank: World development report 1993: investing in health. New York: Oxford University Press; 1993.

3. Murray CJL, Lopez AD: Evidence-based health policy - lessons from the Global Burden of Disease Study. Science 1996, 274:740-743.

4. Murray CJL, Lopez AD, eds: The global burden of disease: a comprehensive assessment of mortality and disability from diseases, injuries and risk factors in 1990 and projected to 2020. Cambridge: Harvard University Press; 1996.

5. Mathers CD, Vos ET, Stevenson CE, Begg SJ: The burden of disease and injury in Australia. Bull World Health Organ 2001, 79:1076-1084.

6. Norman R, Matzopoulos R, Groenewald P, Bradshaw D: The high burden of injuries in South Africa. Bull World Health Organ 2007, 85:695-702.

7. Jankovic S, Vlajinac H, Bjegovic V, Marinkovic J, Sipetic-Grujicic S, MarkovicDenic L, Kocev N, Santric-Milicevic M, Terzic-Supic Z, Maksimovic N, Laaser U: The burden of disease and injury in Serbia. Eur J Public Health 2007, 17:80-85.

8. Michaud CM, McKenna MT, Begg S, Tomijima N, Majmudar M, Bulzacchelli MT, Ebrahim S, Ezzati M, Salomon JA, Kreiser JG, Hogan M, Murray CJ: The burden of disease and injury in the United States 1996. Popul Health Metr 2006, 4:11.

9. United Nations Children's Fund (UNICEF): UNICEF humanitarian action report 2009. Geneva: United Nations Children's Fund (UNICEF); 2009.

10. The United Nations Development Programme (UNDP): Human Development Report 2007/2008: fighting climate change: human solidarity in a divided world. New York: the United Nations Development Programme; 2007

11. World Health Organization: Health Action in Crises: Guinea. Geneva: World Health Organization; 2006.

12. Jha P, Ranson K, Bobadilla JL: Measuring the burden of disease and the cost-effectiveness of health interventions: a case study in Guinea. Washington, D.C.: World Bank; 1996. 
13. Hu G, Sun Z: Poor knowledge translation: an urgent problem in China. Lancet 2008, 372:718.

14. Melgaard B: From research to action: a bridge to be crossed. Bull World Health Organ 2004, 82:723.

15. Department of National Health Information, Ministry of Public Health of Guinea: Guinean Annual Health Statistics Report 2008. Conakry: The Ministry of Public Health of Guinea; 2009.

16. Department of National Health Information, Ministry of Public Health of Guinea: National Health Development Plan 2003 -2012. Conakry: The Ministry of Public Health of Guinea; 2002.

17. Cooper RS, Osotimehin B, Kaufman JS, Forrester T: Disease burden in subSaharan Africa: what should we conclude in the absence of data? Lancet 1998, 351:208-210.

18. Würthwein R, Gbangou A, Sauerborn R, Schmidt CM: Measuring the local burden of disease. A study of years of life lost in sub-Saharan Africa. Int J Epidemiol 2001, 30:501-508.

19. Mhalu FS: Burden of diseases in poor resource countries: meeting the challenges of combating HIV/AIDS, tuberculosis and malaria. Tanzan Health Res Bull 2005, 7:79-84.

20. Bradshaw D, Groenewald P, Laubscher R, Nannan N, Nojilana B, Norman R, Pieterse D, Schneider M, Bourne DE, Timaeus IM, Dorrington R, Johnson L: Initial burden of disease estimates for South Africa, 2000. S Afr Med J 2003, 93:682-688.

21. Cissé A, Souaré IS, Kourouma S, et al: Subacute sclerosing panencephalitis. Study of 32 cases observed in Conakry, Guinea. Bull Soc Pathol Exot 2000, 93:108-110.

22. Mufunda J, Chatora R, Ndambakuwa Y, Nyarango P, Chifamba J, Kosia A Sparks HV: Prevalence of non-communicable diseases in Zimbabwe: results from analysis of data from the National Central Registry and Urban Survey. Ethn Dis 2006, 16:718-722.

23. Mufunda J, Chatora R, Ndambakuwa Y, Nyarango P, Kosia A, Chifamba J, Filipe A, Usman A, Sparks VH: Emerging non-communicable disease epidemic in Africa: preventive measures from the WHO Regional Office for Africa. Ethn Dis 2006, 16:521-526.

24. Naicker S, Plange-Rhule J, Tutt RC, Eastwood JB: Shortage of healthcare workers in developing countries-Africa. Ethn Dis 2009, 19:51-60-64.

25. Anyangwe SC, Mtonga C: Inequities in the global health workforce: the greatest impediment to health in sub-Saharan Africa. Int I Environ Res Public Health 2007, 4:93-100.

26. Habte D, Dussault G, Dovlo D: Challenges confronting the health workforce in sub-Saharan Africa. World Hosp Health Serv 2004, 40:23-6, 40-1.

27. Borse NN, Hyder AA: Call for more research on injury from the developing world: results of a bibliometric analysis. Indian J Med Res 2009, 129:321-326

28. Glew RH: Promoting collaborations between biomedical scholars in the U.S. and sub-Saharan Africa. Exp Biol Med (Maywood) 2008, 233:277-285.

29. Bukachi F, Pakenham-Walsh N: Information technology for health in developing countries. Chest 2007, 132:1624-1630.

30. Baldé AM, Magassouba FB, Barry R, Loua A, Traoré S, Mara F, Mara O, Bangoura O, Camara A, Kouyaté M, Kourouma M, Camara S, Bangoura L, Traoré S, Diallo AK, Diallo AK, Mamy G, Kolomou G, Mamy S, Dieng A, Barry MD, Soumah F, Traoré A, Pieters L, Totté J, Vlietinck AJ: The Guinean traditional medicine in the treatment of HIV/AIDS. Retrovirology 2006, Suppl 1: P6.

\section{Pre-publication history}

The pre-publication history for this paper can be accessed here: http://www.biomedcentral.com/1471-2458/11/436/prepub

\section{doi:10.1186/1471-2458-11-436}

Cite this article as: Mamady and Hu: A step forward for understanding the morbidity burden in Guinea: a national descriptive study. BMC Public Health 2011 11:436.

\section{Submit your next manuscript to BioMed Central and take full advantage of:}

- Convenient online submission

- Thorough peer review

- No space constraints or color figure charges

- Immediate publication on acceptance

- Inclusion in PubMed, CAS, Scopus and Google Scholar

- Research which is freely available for redistribution

Submit your manuscript at www.biomedcentral.com/submit
Ciomed Central 